\title{
CIUDAD POST-ALFABÉTICA
}

\author{
Polyxeni Mantzou \\ Democritus University of Thrace, Department of architecture \\ engineering, Faculty Member \\ https://dx.doi.org/10.12795/astragalo.2017.i23.04
}

\section{RESUMEN}

Las tecnologías digitales instauran nuevas, poderosas mediaciones y traen consigo un cambio de paradigma radical. El mundo alfabético, organizado desde la distancia de la visión, causal, racional, objetivado se convierte en mundo post-alfabético, participativo, fugaz, irracional donde nos encontramos sumergidos. Las conexiones constantes y múltiples hacen que la mediación arquitectónica se vuelve menos relevante. El espacio público de la ciudad, un espacio adquirido y prosperado en la era alfabética, se convierte en escenario temático, mientras sus operaciones se trasladan, en gran parte, al espacio público digital que no reconoce fronteras entre espacio físico publico y privado, y lo invade todo. Nos encontramos en una condición de aporía, pero no del todo reconocida; aporía puede resultar útil para reposicionarnos frente al espacio de la ciudad y trazar nuevos modos de reanimar el espacio publico utilizando las tecnologías digitales y creando entornos híbridos y realidades aumentadas. La ciudad mixta, compleja, híbrida requiere que la arquitectura replantee y amplíe su papel mediador para ofrecerse a mediar entre sujeto y el nuevo contexto aumentado por la hibridación entre mundo físico y digital.

\section{SALIDA}

Salimos fuera para tomar distancia; para separarnos y dejar de formar parte de lo que nos absorbe y nos impregna. Al salir, tenemos la posibilidad de observar, de contemplar, de comprender lo que antes nos comprendía. Durante siglos hemos estado intentado salir para poder especular, para poder comprender el mundo a través de los ojos, de la visión. El mundo prealfabético era un mundo dionisiaco, impreg- 
nante y participativo, del cual era imposible separarse y donde el tacto y el oído construían en gran parte nuestra forma de estar en el mundo. La distancia no se consiguió ni fácilmente ni rápidamente; durante siglos nuestro mundo se fue convirtiendo de pre-alfabético a alfabético y la visión fue adquiriendo cada vez mas primacía, estableciendo divisiones, polos y extremos en lo que antes era una condición indisoluble. El mundo alfabético es un mundo observado desde la distancia, moderno, racional, objetivo y democrático; un mundo basado en la institucionalidad y la frialdad del la visión. La construcción de este mundo se basó en el alfabeto, en el proceso de conversión del mundo en visión que se nos ofrece sin las restricciones espacio-temporales de la sincronía y la sintopía. Sin el alfabeto la causalidad, la objetividad, la linealidad no hubieran sido posibles. El alfabeto fue la condición previa y necesaria pero la industrialización fue la que completó el proceso haciendo posible que la distancia fuera real; el humano moderno ya no tiene que utilizar su energía metabólica para enfrentarse al mundo y controlarlo; no tiene que manipular la tierra, ni siquiera reconocerla como base de referencia indiscutible. El humano moderno se asocia al mundo a través de construcciones teóricas, es decir, desde la distancia de la teoría, del ver desde lejos, como Dios, y no desde la proximidad y la contigüidad del tacto y la inclusión del oído. Sale fuera, pone el mundo en frente, lo ob-jetiviza, lo observa, lo examina, lo convierte en espectáculo y lo controla. Este es un mundo urbano y no rural, un mundo donde las instituciones organizan las relaciones sociales y mediatizan lo personal y lo íntimo. La regularización, la reglamentación de las relaciones es un proceso puramente arquitectónico. El mundo alfabético encuentra en la arquitectura la expresión ideal de su deseo de relacionar, reglamentar y controlar lo que previamente ha sido separado, espaciado, desunido. La ciudad expresa la voluntad de organizar, de separar, distribuir y relacionar para conseguir dominar lo que nos rodea. La metrópolis es el momento de culminación del proceso; lo público adquiere un protagonismo incomparable en la metrópolis. Deambular por la ciudad es a la vez pertenecer y apropiarse de ella; es un derecho y un privilegio que no se le niega a nadie. La ciudad convierte lo público en una condición que aspira a ser equitativa para todos, aunque no siempre lo logra; géneros, edades, razas, nacionalidades, credos que, en el pasado, definían la posibilidad de acceso a espacios comunes, ahora aparecen como indiferentes. Sin embargo, el mundo alfabético es también un mundo de taxonomías y separaciones. La excesiva racionalización, el anhelo de control y regularización de todo, produce exageraciones y distorsiones. La función obtiene prioridad sobre todo; el programa es la organización y el control de lo que todavía no ha sucedido; es el prescribir de lo que sucederá; todo acaba instituido, espaciado, aislado para poder ser reglamentado. Pero llega así un momento de hipérbole, de exceso. La separación óptima se produce con la discretización última; con la conversión del mundo en dígitos que luego se disponen, se combinan, se relacionan para reconstruirlo todo.

\section{ADENTRO}

El exceso de disección, la discretización de todo hasta que quede convertido en partes indiscernibles e infinitamente reconstruibles, en pocas palabras, el mundo digital, produce un cambio 
transcendental en nuestro posicionamiento frente al mundo. Posicionarse de nuevo, situarse, encontrar su sitio en el contexto, ha sido siempre una preocupación arquitectónica.

La arquitectura media y relaciona diferentes condiciones aparentemente opuestas entre sí, siendo los dos polos principales, para los que media, nosotros mismos y el contexto. Se trata, sin lugar a dudas, de una esquematización; ese dipolo es fruto y herencia del mundo alfabético y su anhelo de control. Al mismo tiempo, estos extremos, como todas las esquematizaciones, no son firmes sino que cambian, fluctúan en el tiempo y, por lo tanto, ni nosotros mismos ni el contexto pueden describirse en una estado fijo, estable, resuelto. Aunque siempre se ha pedido a la arquitectura que tome nota de esta fluidez y de la mutabilidad que no se debe ignorar, últimamente, nuestro contexto ha estado cambiando más rápidamente que antes y, por lo tanto, nuestra relación con él se ha afectado. Nuestro emplazamiento, y el proyectar nuestra posición en este mundo, que nunca ha sido estático, pero sí lo parecía a veces, se está ahora transformando tan drásticamente y en tantas direcciones, que todas las prácticas de supervisión y control se vuelven obsoletas, incluso antes de ser concluidas. La arquitectura, con su inercia inherente, no logra adaptarse. El mundo, pero también nuestra relación con él se reorganiza, se reinterpreta, se reconfigura con otros medios. Las conexiones, las mediaciones, las relaciones también pasan a ser el principal propósito de una serie de tecnologías que reinventan las formas de vida.

La ininterrumpida mediación, el estar siempre conectado, transforma el emplaza- miento. Salir, es ya imposible; adentro el flujo es continuo produciendo una atracción irresistible al sujeto que ya no puede, ni quiere, permanecer fuera, observando. Desde dentro, no se puede obtener distancia y leer lo que sucede; no hay forma de entenderlo que no sea a través de participar en ello y experienciarlo. Las organizaciones modernas, fundadas en el control, la disciplina, la separación y la reglamentación, ya están anticuadas. Lo público, ha sido una construcción de un mundo alfabético, un mundo que distingue entre privado y público y organiza las instituciones responsables para que lo público sea equitativo, democrático, justo; o por lo menos, un mundo que aspira a que lo publico sea así. Cuando las mediaciones dejan de ser arquitectónicas, en tanto que edificables, cuando las conexiones empiezan a ser constantes hasta el punto de volverse invisibles y no reconocibles, cuando el mundo pasa a ser postalfabético, ya no es posible localizar lo público. La metrópolis, la madre-polis, deja de ser la más densa estructura de encuentros; los encuentros empiezan a producirse fuera de lugar, dentro del espacio intermedio de la mediación.

Adentro todo es inseparable. El sujeto se encuentra inmerso en el contexto. Los intentos del pasado de objetivar al mundo se abandonan. La conexión se re-establece. La visión deja de ser el sistema perceptivo principal para estar en el mundo. El modelo operativo de la teoría, fruto de la preeminencia de la visión da lugar

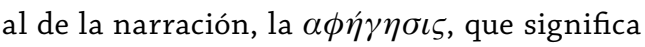
ir delante, adelantarse. Adelantarse pero sin salir fuera; contar desde dentro. La participación sustituye la supervisión y es la palabra que caracteriza el nuevo modelo de estar en el mundo. Distinguir y discernir ya no tiene sentido; 
incluso polos-extremos tradicionales, creados en el pasado alfabético, se someten ahora a la presión de conexiones que anulan su separación. Público y privado no son discernibles. La arquitectura organiza y controla pero las capas de tecnologías superpuestas redistribuyen y alteran. Las instituciones tampoco se mantienen intactas e instituidas; lo que se separaba y se instituía, se hacía en un sitio determinado, ahora se puede hacer en todos los sitios o más bien desde todos los sitios, pero en ningún sitio localizable. Junto con las instituciones -profundamente criticadas por su totalitarismo que homogeneiza y anula las diferencias y por la excesiva disciplina que ejercen en su deseo-pretexto de ser equitativas- que ahora se diluyen hasta llegar a ser ilocalizables, se diluye el entendimiento de lo público de la etapa anterior.

Los encuentros físicos no pierden su atracción, pero la esfera de la interacción de los individuos se dilata y empieza a ser igual de atractiva más allá de su presencia corporal, física. Nuevos medios y nuevos estatutos nos posicionan en el mundo. Este mundo de los medios sin embargo no es un mundo público; no es equitativo; no se ofrece a todos; ni siquiera pretende hacerlo; no se resiste a la exclusión. Es un mundo colectivo, participativo, pero no público. Las colectividades, casi siempre llenas de buenas intenciones, progresivamente sustituyen lo que antes pertenecía y se ofrecía de forma igual a todos; las colectividades se agrupan porque comparten intereses o características comunes; no son abiertas, ni públicas, ni tienen acceso a ellas todos. El mundo post-alfabético reclama características del mundo tribal de la era prealfabética. Opera desde dentro, sin la distancia y la frialdad de la teoría. No es equidistante, ni objetivo; es un mundo caliente, de reacciones inmediatas y espontáneas, de explicaciones dispersas y no causativas.

Los colectivos sustituyen a las estructuras públicas sin que se haga siempre visible el hecho que los colectivos se basan a la similitud, al hecho de reconocerse a los demás y ser reconocido por ellos. La diferencia y la discrepancia queda excluida. Los colectivos pueden apoyar o no la diferencia, pero depende de ellos, de sus prioridades y de su entendimiento de ellas; el acceso a las colectividades no es incondicional. El espacio público de la metrópolis y las instituciones que lo constituyen ha operado como un espacio de encuentro entre los que no comparten los mismos intereses, las mismas posibilidades, los mismos anhelos. Es más el espacio público de la metrópolis es un espacio de encuentro entre ascendientes y los descendientes; entre pasado y futuro; lo recibimos de los que nos han precedido para entregárselo a los que vienen. La excesiva reglamentación, a veces, y la austera disciplina que resulta homogeneizadora, no borra su disposición equitativa hacía todos.

Adentro, la ciudad no desaparece; ni siquiera se nota el efecto de las tecnologías que superponen capas de encuentros y densidad de operaciones inmateriales; pero su relevancia, el ambiente de la ciudad se afecta. Las formas de vida del mundo post-alfabético despojan de la ciudad su capacidad seductora; la convierten en escenario de fondo, visible y presente incluso más que antes, pero de segundo orden. Lo público se debilita, la ciudad se convierte en una imagen elusiva; está pero no reglamenta, no relaciona, no conecta y lo más importante no condiciona ni configura las formas de vida. 
El espacio deja de ser generador de cambios y se convierte en reflector; los cambios que suceden se proyectan en la ciudad, pero como alusión elusiva.

\section{FUERA DE CAMPO}

Hemos estado encuadrados durante largo tiempo. Es nuestro afán de control lo que nos encuadra sin darnos cuenta. La arquitectura es quizás el mecanismo de encuadre más importante que hemos podido desarrollar. Con la arquitectura organizamos nuestro entorno, lo enmarcado, lo controlamos, lo dominamos, lo domesticamos y lo poseemos. Mientras podamos ver el marco, no estamos del todo enmarcados; es cuando el marco desaparece, cuando se vuelve invisible para nosotros y percibimos la imagen enmarcada como la imagen total que estamos perdidos.

El marco es inevitable, pero también es posible moverse alrededor de este, romper, distorsionar o deformarlo, y así encontrar o formar múltiples nuevos marcos. Es a través de la arquitectura y no hacia la arquitectura que nos colocamos en esta búsqueda de oportunidades y perspectivas de replanteamiento.

Puede decirse que la arquitectura produjo casi literalmente, incluso obscenamente, y también tradujo los mecanismos de encuadre de cada época. La organización de la ciudad moderna es un encuadre arquitectónico que ilustra los encuadres de su época. La distancia, la supervisión, el control, pero también la distribución, la racionalidad, la imparcialidad, se tradujeron en ciudad. La distancia no sólo es operativa, también es conceptual; el arquitecto era indiferente a la emotividad engendrada por especificidades idiosincrásicas, de las que se separó y se disoció para operar sólo desde una postura racional, lógica.

Por supuesto, el enfoque alfabético, moderno es indiferente a lo específico y lo local; es cosmopolita; la comprensión internacional de la vida propone arquitecturas genéricas, comunes, descontextualizadas que se pueden copiar y transferir a cualquier contexto, ya que finalmente tienen como objetivo la homogeneización de todos ellos. Las rarezas y las emociones, los gestos únicos eran eso, singularidades desviadas que refuerzan, por contradicción, la norma. Dogmas éticos e ideológicos tales como la funcionalidad, la transparencia, la sinceridad, la austeridad se transformaron en el marco de la arquitectura moderna, que por ser tan perfectamente colocado, durante mucho tiempo, se perdió de vista. Disposición programática y programa de distribuciones funcionales, pro-grama en tanto que escribir pero también instituir de antemano; así era la aproximación moderna a la arquitectura entendida como sistema organizacional del mundo. En este delirio de taxonomía, las ciudades se zonifican, las calles se clasifican, incluso cada edificio se analiza, categoriza y se asigna a un tipo; se presumen organizaciones fijas y estables. Se trata de reglamentar el espacio y a la vez programar, prescribir el tiempo. Sin embargo, con el paso del tiempo, el parámetro obliviado de inestabilidad, alteración y duración, devuelve el golpe sin piedad.

\section{UMBRAL}

El espacio público se entiende a veces en contraposición con el espacio privado; es impro- 
bable comprender al público si no se considera en relación con su par antitético, lo privado. La arquitectura no sólo ha mediado para este dipolo preeminente, pero también ha sido el común principio y fin, el espacio intermedio de conexión, que configura y define los encuentros; el límite y la interfaz que condiciona la relación de dos sistemas apartados y construye transiciones y umbrales. La genealogía de estos umbrales, el grado de su profundidad, es una característica distintiva e ilustrativa de diferentes culturas y sociedades. Organizar y relacionar el espacio público con el espacio privado es reflejar y configurar la publicidad, la privacidad e incluso la intimidad. La arquitectura como principal mecanismo mediador de muchos dipolos espaciales, como el público-privado, se ve afectada por la inmediatez que las tecnologías digitales están insertado; la inmediatez digital suprime la polaridad de los dipolos siendo ahora las conexiones y vínculos entre ellos permanentes y múltiples. Y es que la mediación digital es inmediata como resultado de su capacidad para habitar en un intervalo demasiado corto para que nosotros lo percibiéramos y también por su carencia de localización, es decir, el hecho que se produzca en una dimensión imposible de localizar.

Las consecuencias de la implementación y el crecimiento de la mediación digital son importantes para todas las demás mediaciones, las cuales aparentan como mediadoras y no como inmediatas. Lo digital hace posible la mediación sin lugar y casi sin tiempo; crea una mediación invisible, imperceptible y que suprime todos los intervalos e intermediarios. La ciudad y especialmente el espacio público, urbano, se ve afectada y sometida a cambios.
De acuerdo con las Naciones Unidas “a mediados de 2009, el número de personas que viven en zonas urbanas (3.42 mil millones) había superado el número de personas viviendo en zonas rurales (3,41 mil millones) y desde entonces el mundo se ha vuelto más urbano que rural." ${ }^{1}$

La ciudad, incluso en la era post-alfabética permanece importante para la civilización. Desde la fase tribal de la aldea hasta la etapa civil, es decir, la construcción de urbs y, más adelante de la metrópolis, la disposición de la población en el espacio es de extrema importancia para la humanidad. Las estructuras nómadas se sustituyeron por las sedentarias, cuando el cultivo fue posible y, como resultado, se originó la cultura. La fase tribal corresponde a la circunstancia pre-alfabética, mientras que la ciudad se asocia con la condición alfabética en la que la organización, categorización y distinción se expresa mediante la institucionalización progresiva de la vida cotidiana. La urbanidad no se refiere sólo a la conglomeración, sino a la comunidad, el compartir un terreno común y pertenecer a algún lugar, formar parte y formarse como parte de un todo. Es a través de este proceso organizacional que las sociedades alcanzan una etapa avanzada de desarrollo.

Por un lado, lo urbano se extiende continuamente pero, por otro lado, se trastorna rápidamente debido a la proliferación de medios sociales digitales. Comercio online, entretenimiento digital, archivos digitales, teletrabajo, enseñanza a distancia y casi todas las operaciones urbanas y las tipologías correspondientes

1 http://www.un.org/en/development/desa/population/ publications/urbanization/urban-rural.shtml 
que se utilizaban para definir la ciudad, poco a poco se han ido trasladando desde el espacio físico urbano a un medio omnipresente, sin raíces, disperso e ilocalizable, dejando el espacio urbano injustificado y desolado. El espacio público y especialmente el centro de las grandes ciudades europeas encuentra en la tematización y en la gentrificación su única razón de ser. Se ofrece así como comodidad a un uso que parece turístico incluso cuando se refiere a sus propios habitantes y que conquista los centros históricos. El ocio temático es la forma de conectarse con la historia y consumirla como reminiscencia del pasado. Por otra parte, el sentido de pertenencia, la comunidad que el espacio físico urbano puede engendrar en el en el ámbito digital se despojan de la profundidad que tenían; los encuentros dispersos ocurren sin dejar rastro y la memoria se transforma en un archivo borrable.

La aldea global de McLuhan (1962) no era una predicción falsa; en muchos sentidos, nuestro espacio público, aunque las ciudades siguen atrayendo las poblaciones de todo el mundo, se parece al de una aldea global. Funciona como una aldea, donde los rumores corren sin que se hayan verificado los hechos, donde el acceso queda restringido para miembros de ciertos colectivos, donde el ser popular puede con la equidad de derechos. Nos sumergimos a este nuevo espacio y no racionalizamos nuestra relación con él; no lo abordamos, su desarrollo no es espacial y su tiempo no es perceptible; entramos en una condición sin distancia, ni objetivación, sin organizar, distribuir e imponer nuestro plan. Es igual que la aldea para el aldeano; nos adaptamos a su "topografía digital”, a sus singularidades, como antes las aldeas lo hacían con la topografía física. Sin embargo, se trata de una aldea global; lo local se ha superpuesto al cosmopolitismo; el mundo se reconstruye interconectado pero disminuido, contiguo pero encogido.

En nuestra era digital, el espacio público de la ciudad no se delimita ni se define de modo comprensible; se expande, colonizando lo que solía ser privado e incluso íntimo. Los sujetos contemporáneos ya no perciben el espacio público como un espacio físico, definido y regulado por elementos arquitectónicos; el espacio público inmaterial de lo digital atraviesa e impregna las fronteras materiales y los umbrales tradicionales anulando las anteriores definiciones arquitectónicas de público y privado.

Sin embargo, si el espacio público digital invade el espacio físico privado, también se puede integrar al espacio físico público; una operación que puede ser beneficiosa para ambos. Los encuentros reales y virtuales se pueden combinar, fusionar $y$, por lo tanto, enriquecer; los límites y umbrales entre público y privado pueden permanecer operativos pero, al mismo tiempo, las operaciones públicas pueden aplicarse más allá de las limitaciones espacio-temporales.

La inmediatez y la ubicuidad del espacio público digital (Virilio, 1984) en el caso de los espacios públicos híbridos puede reforzar el espacio público físico, sin borrar el sentido de emplazamiento. Al mismo tiempo, pueden establecerse fronteras y umbrales operativos en un contexto mixto, híbrido, que proporciona experiencias diversificadas y enriquecedoras. La ciudad híbrida puede resultar en 
un proyecto extremadamente beneficioso para el espacio público; donde lo público no se diluye en lo privado, sino que al contrario, las tecnologías digitales se aplican para reforzar el espacio publico físico de la ciudad y ofrecer nuevas posibilidades. El proyecto de la ciudad híbrida supone un cambio radical en los conceptos y las estrategias proyectuales; supone la aceptación de los cambios que están ocurriendo como parte de los desafíos que los arquitectos tendrán que afrontar en el futuro; supone asimismo no sólo proyectar con mixed media pero proyectar para una realidad mixta, inestable, fluida, pero también llena de nuevas peripecias, es decir un mundo donde se encuentran y se juntan distintas realidades, para configurar un mundo umbral.

\section{APORÍA}

Aporía describe la falta de pasaje y de recursos; la ausencia de poros (la palabra poros en griego significa a la vez pasaje y recurso). La palabra tiene tres acepciones en griego: $i)$ es la ausencia de pasaje, el sin salida; ii) la duda, la vacilación, el no poder atravesar y seguir adelante; iii) la pobreza que es el resultado de la falta de recursos a causa de la falta de pasajes.

Aporía es nuestro estado en la era postalfabética, en la era que nos encontramos cuando las tecnologías digitales se han plenamente instalado. El mundo progresivamente se fue volviendo menos comprensible y más elusivo. Las formas de vida se desvelan como construcciones propias, efímeras, sin permanencia, ni estabilidad; el mundo ya no se puede analizar desde la distancia, objetivar desde la lejanía; volvemos a encontrarnos diluidos en él; inter- conectados hasta el punto que la separación se vuelve imposible.

Aporía es también la condición en la que se encuentra la ciudad contemporánea, que no ha perdido centralidad ni importancia, pero se vuelve elusiva, ya que su entramado se pierde en el fondo y se oculta por las capas digitales que se superponen a ella. La ciudad despojada de sus espacios y funciones públicas a causa de la proliferación de lo digital, podría ser una ciudad aumentada, híbrida, compleja y mixta. Eso supondría que la arquitectura proyectara lo analógico junto con lo digital, aceptándolo como el entorno indistinguible que ya es. La ciudad aumentada es una ciudad donde lo digital refuerza el espacio físico, donde coexisten diferentes aspectos de los distintos modos de configurar relaciones y organizar funciones. Las ciudades híbridas pueden ofrecer proximidad física, sentido de pertenencia y comunidad $y$, al mismo tiempo, conectar comunidades y colectividades distantes, ampliar sus horizontes y dilatar las restricciones espaciales. Los procesos urbanos que combinan la presencia física y digital pueden reanimar los espacios urbanos $y$, al mismo tiempo, pueden permitir a los aldeanos globales convertirse en ciudadanos del mundo, cosmopolitas.

Aporía caracteriza todas las épocas de cambio de paradigma; es de esperar que cuando las certezas y los automatismos dejan de ser operativos, el sujeto se encuentra parado, sin saber por donde seguir, sin poder encontrar su pasaje para reposicionarse y asimilar los cambios. No es el caso de esta época; aunque estamos ante un cambio de paradigma radical, éste se ha producido sin rupturas ni quiebras. 
Salir fuera, entrar en aporía es un proceso alfabético, que el mundo post-alfabético atenúa. El sujeto de la era post-alfabética tiene conciencia de la época previa y a veces se incomoda por la ausencia de control, de visibilidad, de predicción, de distancia, de causalidad y racionalidad en lo que le rodea. Aún así, no esta siempre preparado para salir de su estado sumergido y disfrutar de lo que la aporía le puede proporcionar. La arquitectura y asimismo la ciudad tiene la necesidad de replantear las infinitas posibilidades, que le ofrece esta nueva etapa, desde la aporía. Es una condición adecuada para comprender, replantear y trazar un nuevo modo de posicionarnos en la realidad amplificada, de condicionar la relación con éste entorno aumentado y de mediatizar nuestra experiencia en este mundo híbrido.

\section{BIBLIOGRAFÍA}

Arendt, H. (1958) The Human Condition.

University of Chicago Press, Chicago

Carpo, M. (2011) The Alphabet and the Algorithm, MIT Press, Cambridge MA

Foucault, M. (1994) The order of things. Ed. Vintage Books, New York

Mantzou, P. (2017) Aporia in architecture: What now?, Epikentro Publishers, Greece

McLuhan, M. (1962) The Gutenberg Galaxy: The making of typographical man. University of Toronto Press, Canada

McLuhan, M. (1964) Understanding Media, The extensions of man, McGraw-Hill, NY

Ong, W. (1982) Orality and Literacy:The

Tecnologizing of the Word. Ed. Routledge, London

Simmel, G. (1997) Bridge and Door. In Frisby, D. and Featherstone, M. (Eds), Simmel on culture. Ed. Sage, London

Virilio, P.(1984) Lost Dimension. Ed. Semiotext, USA 


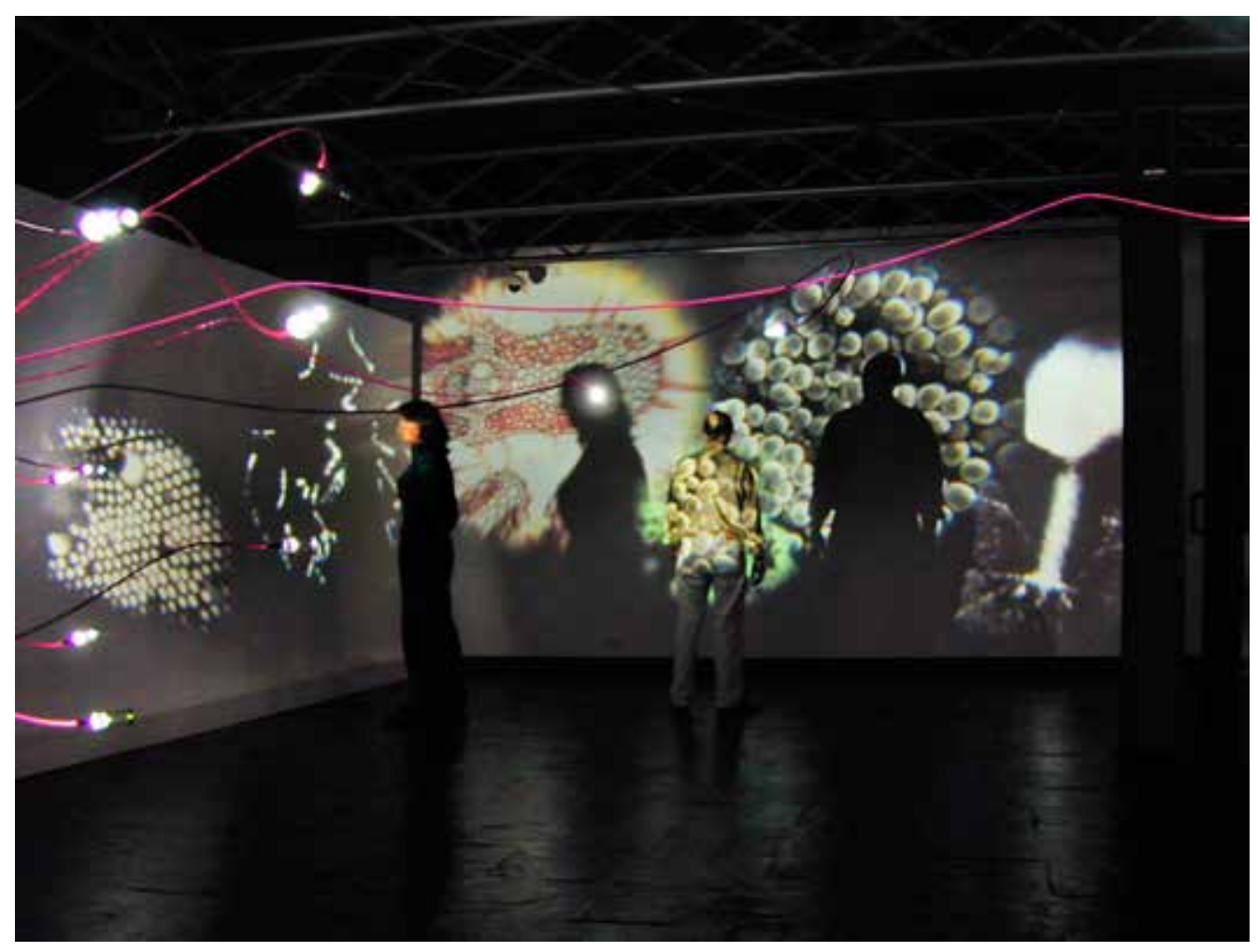

